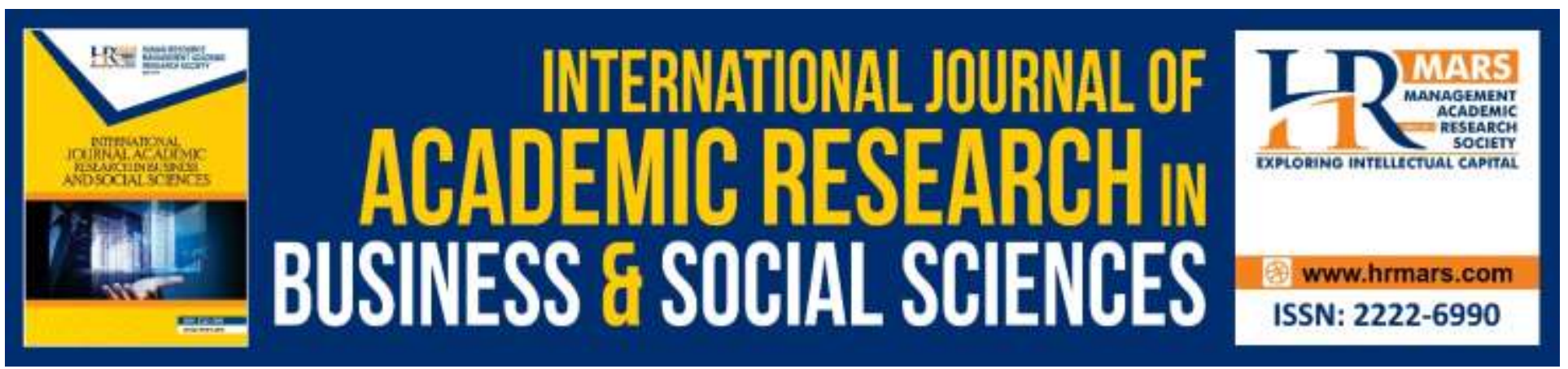

\title{
Academic's Perceptions of Barriers and Enablers to Oral Health Research
}

Noor Nazahiah Bakri, Ahmad Nadzri Mohamad, Mohd Masood, Mas Suryalis

To Link this Article: http://dx.doi.org/10.6007/IJARBSS/v9-i13/6249

DOI: $10.6007 /$ IJARBSS/v9-i13/6249

Received: 13 March 2019, Revised: 19 June 2019, Accepted: 30 July 2019

Published Online: 23 August 2019

In-Text Citation: (Bakri, Mohamad, Masood, \& Suryalis, 2019)

To Cite this Article: Bakri, N. N., Mohamad, A. N., Masood, M., \& Suryalis, M. (2019). Academic's Perceptions of Barriers and Enablers to Oral Health Research. International Journal of Academic Research in Business and Social Sciences, 9(13), 134-145.

Copyright: (C) 2019 The Author(s)

Published by Human Resource Management Academic Research Society (www.hrmars.com)

This article is published under the Creative Commons Attribution (CC BY 4.0) license. Anyone may reproduce, distribute, translate and create derivative works of this article (for both commercial and non-commercial purposes), subject to full attribution to the original publication and authors. The full terms of this license may be seen

at: http://creativecommons.org/licences/by/4.0/legalcode

Special Issue: Revolutionizing Education: Challenges, Innovation, Collaboration, 2019, Pg. 134 - 145 http://hrmars.com/index.php/pages/detail/IJARBSS

JOURNAL HOMEPAGE

Full Terms \& Conditions of access and use can be found at http://hrmars.com/index.php/pages/detail/publication-ethics 


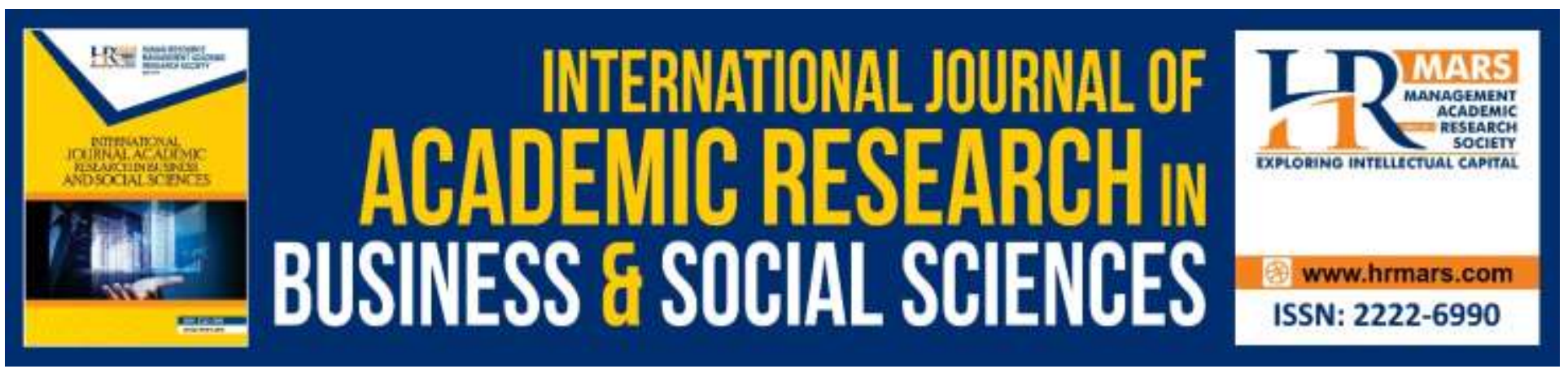

\title{
Academic's Perceptions of Barriers and Enablers to Oral Health Research
}

\author{
Noor Nazahiah Bakri ${ }^{1}$, Ahmad Nadzri Mohamad², Mohd Masood ${ }^{3}$, \\ Mas Suryalis ${ }^{1}$ \\ ${ }^{1}$ Faculty of Dentistry, Universiti Teknologi MARA, Sungai Buloh Campus, 42700 Sungai Buloh, \\ Selangor, Malaysia, ${ }^{2}$ Faculty of Information Management, Universiti Teknologi MARA, \\ UiTM Puncak Perdana, 40150 Shah Alam, Selangor, Malaysia, ${ }^{3}$ Department of Dentistry and Oral \\ Health, La Trobe Rural Health School, La Trobe University, Melbourne, 3550, Australia
}

\begin{abstract}
Background: Knowledge productivity and research engagement are essential to ascertain that the dental profession is at the frontier of a new discovery. Analysis of published papers on the Scopus database revealed that the dental field output from Malaysia is only a meagre $0.46 \%$ of the world's dental fields research output. This relatively low research output is a considerable hindrance to the prevention and management of oral ill health and its associated problems in Malaysia. This study aimed to identify the main motivational factors and barriers faced by Malaysian dental academics in conducting dental research. Method: An audio-recorded semi-structured face to face interview was conducted among academics in a public Malaysian institution to identify barriers and motivation factors for undertaking research activity and publication. Ten dental academics (Response rate $=83 \%$ ) from various specialty backgrounds participated in this study. Qualitative data were analysed via thematic analysis, involving open- and close- coding, followed by identification of emerging themes. Results: The main motivating factors to undertake research activity and publishing reported by respondents were self-satisfaction, knowledge-improvement, information-sharing, encouragement from colleagues/institution, career progression and institution's requirement. The main barriers to undertaking research activities and publication were a time constraint, inadequate facilities, financial limitation, poor training in academic writing, as well as a lack of incentives or rewards. Factors affecting the choice of journal submission included Journal indexing (ISI/Scopus/WoS), reviewing time, journal impact factor, and publication fees. Conclusion: Findings of this study provide recommendations for stakeholders to overcome barriers to research and publication, leading to a more research-conducive environment in Malaysia.
\end{abstract}

Keywords: Academics, Motivation Factors, Oral-Health Research, Research Activity, Research Productivity 
INTERNATIONAL JOURNAL OF ACADEMIC RESEARCH IN BUSINESS AND SOCIAL SCIENCES

Vol. 9, No. 13, Special Issue: Revolutionizing Education: Challenges, Innovation, Collaboration., 2019, E-ISSN: 2222-6990 @ 2019 HRMARS

\section{Introduction}

Research engagement is essential to ascertain that the dental profession is at the frontier of new discoveries. Such research-led discoveries are crucial as the profession aims to uphold high-quality patient care that places an emphasis on evidence-based practice.

In Malaysia, research activities constitute the main agenda of the country's educational development plan (Ibrahim, 2010; Ministry of Education Malaysia, 2015). Initiatives to promote the conduct and publication of research among academicians are ongoing, as the country aspires to contribute towards global development of scientific knowledge.

While the productivity of research activities in other fields in Malaysia was found promising (Suryani et al., 2013; Elservier Research Intelligence, 2015), a similar scenario was not described for dentistry. It was found that the dental field output from Malaysia is only a meagre $0.46 \%$ of the world's overall value. Although the number of local dental academicians were found higher than other developed countries, Malaysia was ranked 36 out of 100 countries in terms of research output, which was lower than some developing countries in Asia.

Pau et al. (2017) reported that research and development skills and aptitude were associated with an older response, Ph.D. qualification and more experience in academic years. In order to create a conducive environment that promotes the development of research culture among Malaysian dental academicians, barriers that limit research activities need to be identified. This study was undertaken to determine the motivational factors and barriers to conducting and publishing oral health research faced by academicians in Malaysian dental institutions. Findings of this study would provide important information for stakeholders in addressing the issues related to low oral health research output among dental academicians in this country.

\section{Method}

12 academicians from various specialty backgrounds in a Malaysian public university were invited to participate in a face-to-face interview from July 2017 to March 2018. The interview was conducted in their own office, and audio-recorded with permission. A semi-structured questionnaire, developed from previous literature (Grossman \& Naidoo, 2012; loannidou et al., 2013; Shepherd et al., 2001) was used during the interview. Open- and close-ended questions (Table 1 ) were used to identify barriers and motivation factors for conducting and publishing research. The questions were divided into 5 parts (Part 1: Sociodemographic characteristics; Part 2: Educational background and working experience; Part 3: Research and publication backgrounds; Part 4: Motivating factor to undertake research activity and publication; Part 5: Barriers to undertaking research activity and publication.

A verbatim transcription was produced following the interview. Qualitative data were then analysed via thematic analysis, involving open- and close- coding and followed by identification of emerging themes. The initial coding scheme and the identified themes were evaluated and discussed among the researchers until consensus was achieved. Ethical approval was granted from the Universiti Teknologi MARA Ethic Committee (REC/62/17). 
Table 1. Example of open and closed-ended questions

Open-ended questions

What is your main motivator to undertake research activity?

What do you consider as barriers to undertaking research activities for yourself?

What factors do you look at when you choose the journals that you want to submit?
Closed-ended questions

Do you think we have adequate research facilities in this institution?

Do you think the incentives from university/ organisation is lacking to motivate you to publish?

How about the timing of the review process? Does it affect your choice?

\section{Findings}

10 out of 12 (response rate: 83\%) academicians agreed to participate in this study. All invited participants came from a variety of specialty to allow various perspective on the motivation and barrier of research activity and productivity. They were two from dental public health, two from restorative and each one from paediatric dentistry, oral radiology, oral surgery, periodontology, basic medical science, and orthodontic specialty. The sociodemographic of study participant is presented in Table 2. $20 \%$ of study participant were male, and $80 \%$ were female. The mean age of study participants was 45.8 which range from 34 years -65 years old. The mean years of academic experience were 11.2 years with a range of $2-33$ years of experience. $40 \%$ of the study participant with Ph.D. qualification and the remaining $60 \%$ with a master degree in their specialty. $80 \%$ of study participants were Malaysian, $10 \%$ was Malaysian permanent residents and $10 \%$ was expatriate.

Table 2. Sociodemographic of study participants

\begin{tabular}{|l|c|c|}
\hline Sociodemographic & Range & Mean \\
\hline Age of academic & $34-65$ & 45.8 \\
\hline $\begin{array}{l}\text { Years } \\
\text { experience }\end{array}$ & $2-33$ & 11.2 \\
\hline & $\mathrm{n}(\%)$ & \\
\hline $\begin{array}{l}\text { Gender } \\
\text { Male }\end{array}$ & $2(20 \%)$ & \\
Female & $8(80 \%)$ & \\
\hline Qualification & $\mathrm{n}(\%)$ & \\
PhD & $4(40 \%)$ & \\
Master & $6(60 \%)$ & \\
\hline Citizenship status & $8(80 \%)$ & \\
Malaysian & $1(10 \%)$ & \\
Permanent Resident & $1(10 \%)$ & \\
Expatriate & & \\
\hline
\end{tabular}




\section{Motivation to Undertaking Research Activities and Publication}

All participants agreed ( $n=10,100 \%$ ) that Malaysian academics should actively involve in research activities. Figure 1 shows the main motivation for research activities perceived by study participants.

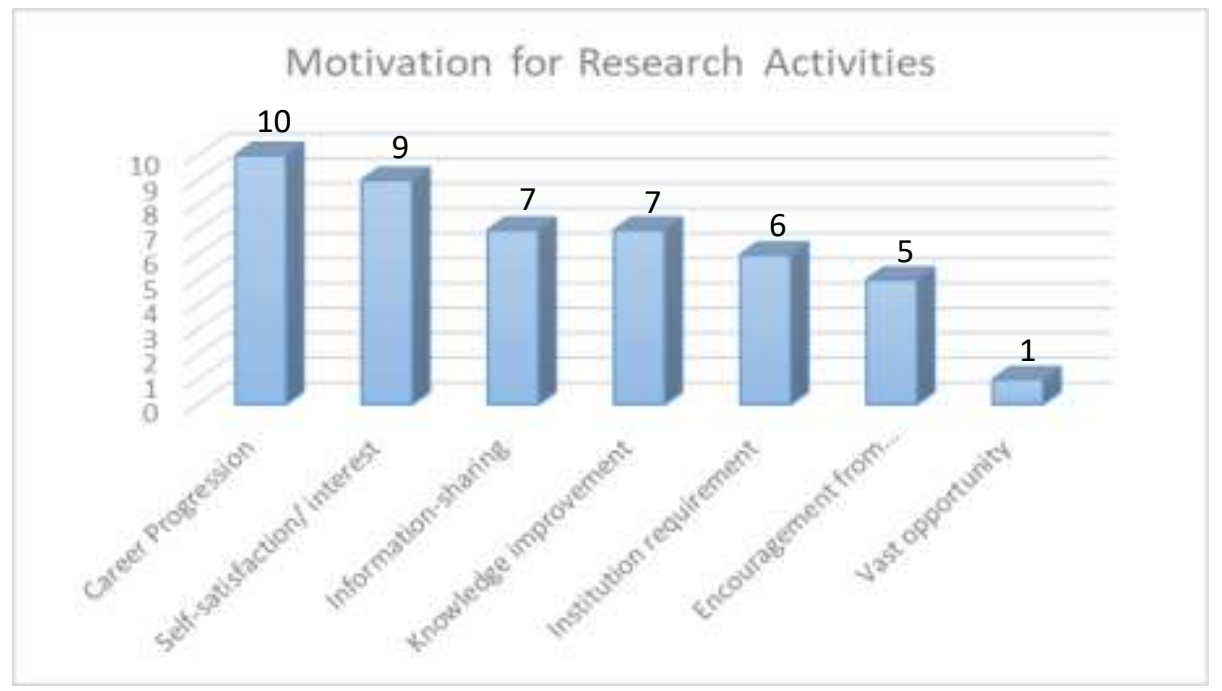

Fig. 1 Main motivating factors for conducting and publishing research reported by study participants.

\section{Motivation 1: Career Progression}

All respondents $(n=10,100 \%)$ reported that their main motivation to undertake research activities and publication was career progression.

"For career enhancement, that is one of the factors....

"Carrier development. We have this as a requirement to be promoted"

"For the time being, that main motivation is for sure to get $A / P . "$

\section{Motivation 2: Self-Satisfaction/ Self-interest}

Most respondents ( $n=9,90 \%$ ) quoted that their main motivation to undertake research activities and publication was self-satisfaction or self-interest.

"When you do a project you would want to publish and gain satisfaction." "Of course... self-satisfaction ... knowing that you have come out with something that hopefully you can share..."

\section{Motivation 3: Information-sharing}

Most respondents ( $n=7,70 \%$ ) also expressed that their main motivation to undertake research activities and publication was information-sharing.

"Main motivation is to share whatever that you already have put effort on" 


\section{Motivation 4: Knowledge Improvement}

Most respondents $(n=7,70 \%)$ cited that their main motivation to undertake research activities and publication was for knowledge improvement.

"I like to find new findings and knowledge from research."

\section{Motivation 5: Institution Requirement}

Institution requirement and having a key performance indicator (KPI) requirement set by the institution is also cited by most respondents $(n=6,60 \%)$ as one of the main motivation to undertake research activities and publication.

"...it helps with my application for grants and employment contract renewal.... I don't like publishing, but I know I have to do it."

\section{Motivation 6: Encouragement from Colleagues/Institution/ Others}

About half participants ( $n=5,50 \%$ ) responded that having encouragement from colleagues, institution or others as among one of the motivation factors to undertake research activities and publication.

"I got a lot of encouragement from various parties, but basically it is from my family because most of them are academicians."

"Actually the motivating factors usually come from the boss. I believe if you did the work and you receive the appreciation from your friends/Dean/the Admin, this will encourage you to do more and more."

\section{Others Motivation: Vast Opportunity/ Networking in the University Setting}

One of the respondents ( $n=1,10 \%$ ) related that having a vast opportunity and networking in the university setting motivates him to undertake research activities and publication.

"I have not been exposed in research throughout my military carrier and during my teaching experience in private university. Although we could collaborate with other universities I didn't have time ... Now I find there are opportunities for networking and everything is within reach."

\section{Barrier to Undertaking Research Activities and Publication}

All participants agreed $(n=10,100 \%)$ that they have encountered a few challenges in undertaking research activities and publication. Figure 2 shows the main barriers to undertaking and publishing research reported by the study participants. 


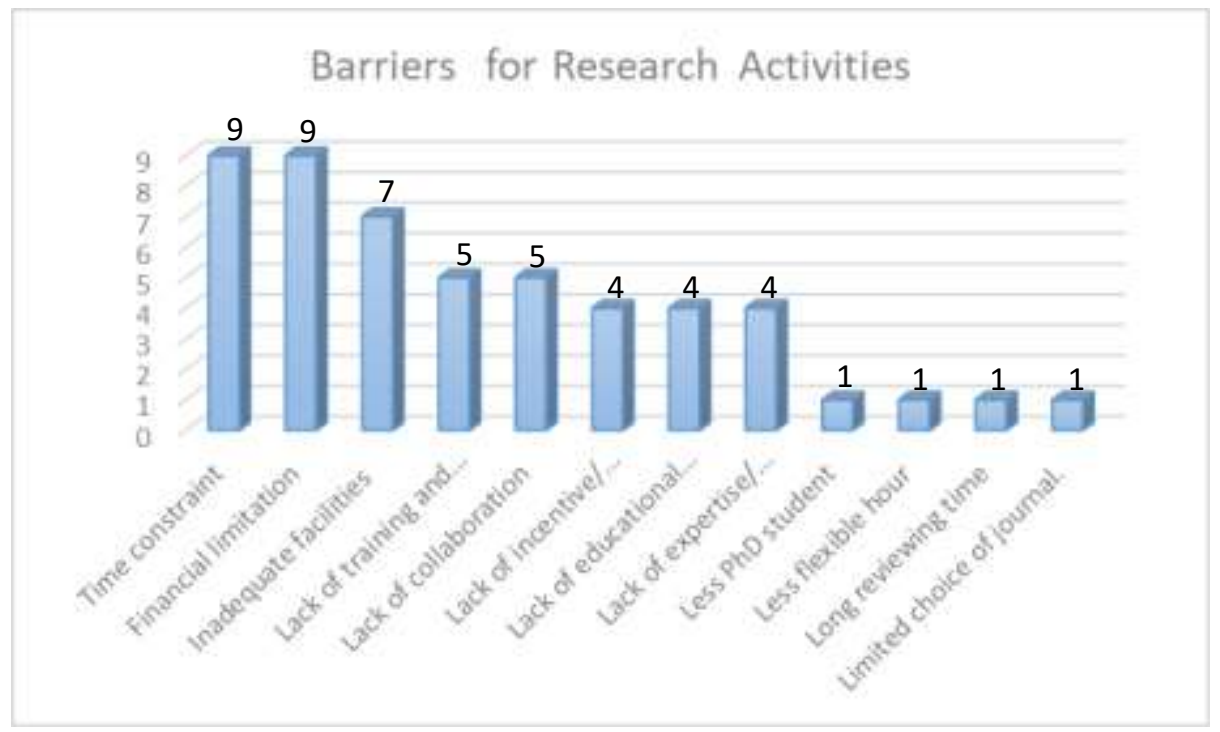

Fig. 2 Main barriers to research activities reported by study participants.

\section{Time Constraint}

Most Malaysia academic ( $n=9,90 \%$ ) emphasized that one of the main barriers to undertake research activities and publication was a time constraint.

"You don't have enough time because almost all of the time will be allocated for teaching and supervision. Even if you have time, you still need to do some admin work."

"Lecturers from other faculties don't teach as much as we do. Our clinical supervision workload is too much."

\section{Barrier 2: Financial limitation}

Financial limitation and lack of funding $(n=9,90 \%)$ were also reported as one of the main barriers to undertake research activities and publication.

"The grant and financial support are quite scarce."

"Most of the journals you have to pay for quite some money."

\section{Barrier 3: Inadequate Facilities}

Most respondents $(n=7,70 \%)$ reported that one of the barriers to undertake research activities and publication was inadequate facilities.

"But most of the time the equipment is spoilt... mainly due to under usage rather than over usage... and there is not enough money to get it repaired".

\section{Barrier 4: Lack of Training and Knowledge on Research Methodology/ Scientific Writing.}

Half of the respondents $(n=5,50 \%)$ quoted that their barrier to undertaking research activities and publication is a lack of training and knowledge on research methodology and/or scientific writing. 
INTERNATIONAL JOURNAL OF ACADEMIC RESEARCH IN BUSINESS AND SOCIAL SCIENCES

Vol. 9, No. 13, Special Issue: Revolutionizing Education: Challenges, Innovation, Collaboration., 2019, E-ISSN: 2222-6990 @ 2019 HRMARS

"Some may be gifted in writing, but we are talking about academic writing, which is totally different." "I think it will be a bit of a problem for Malaysians to write in English. We have to ask somebody to do editing."

\section{Barrier 5: Lack of Collaboration}

Lack of collaboration was also cited as one of the barrier to undertake research activities and publication by the study participants $(n=5,50 \%)$.

"People are very reluctant to contributing ... mainly because of time constraint and they want something beneficial... such as recognition as an author in the publication".

\section{Barrier 6: Lack of Incentive/ Appreciation}

A few respondents $(n=4,40 \%)$ reported that lack of incentive and appreciation from the institution as one of the demotivating factors to undertake research activities and publication.

"The university needs to upgrade the incentive or make it more competitive or more appealing, or rewarding for people who publish more or attain more grant."

\section{Barrier 7: Lack of Educational Resources}

Lack of educational resources were also being highlighted as one of the barriers to undertake research activities and publication by the respondents $(n=4,40 \%)$.

"I find that some of the journals that I want to read, I have to pay or be a member. It's quite difficult."

\section{Barrier 8: Lack of Expertise/ Supporting Staff in Lab Work}

Some respondents $(n=4,40 \%)$ related having a lack of expertise and supporting/well-trained staff as one of the barriers to undertaking research activities and publication.

"We have the facilities but expertise in handling the lab is not good enough."

\section{Other Barriers}

Other barriers quoted by one of the study participants were less Ph.D. student in dentistry, less flexible hour for academics, long reviewing time and limited choice of journals ( $n=1,10 \%)$.

\section{Factors Affecting the Choice of Journal}

Factors that affect the choice of the journal cited by participants were listed in Table 3 . 
Table 3. Factors affecting the choice for journal submission.

\section{Discussion}

\begin{tabular}{l}
\hline Journal indexing (ISI/Scopus/ WoS) \\
\hline Reviewing time \\
\hline Journal impact factor \\
\hline Publication fees \\
\hline Open access/ high visibility \\
\hline Subject-related journal \\
\hline Journal ranking \\
\hline Likelihood of being accepted. \\
\hline
\end{tabular}

Study participants agreed that one of the 'push factor' to do research and publish scientific paper was career progression and institution requirement. Most Malaysian institution has set a minimal key performance indicator (KPI) to be achieved for each year by academics. The scientific publication has been used to measure research productivity and being one of the performance indicator and criteria to be considered for promotion for academics. The same method has been practiced in other countries such as United State, Australia and Europe (Adam \& Griliches, 1998; Avkiran, 1999; Butler, 2003; Van Looy, 2013). These indirectly motivate academics in Malaysia to reach the minimum requirement and become relevant as academic in university. On the other hand, self-satisfaction and self-interest are seen as an internal factor that builds in academic' mind-set which relates to research enthusiasm. Research enthusiasm refers to the internal strength of researchers to involve actively in knowledge production. It can be viewed as the determination, excitement and great interest to learn and produce research output. In education, for instance, teacher enthusiasm impacts students' performance, interest and result in the classroom (Kim \& Schallert, 2014; Kunter et al., 2011). Therefore, this study suggests that research enthusiasm among academic is a vital internal factor that needs to be polished in line with career responsibility and commitments.

The finding from this study highlighted that the main barriers to undertakes research activities and publication among dental academics in Malaysia were a time constraint. Most of the dental academics in dental schools have to conduct research and deliver oral health care services at the same time. The time involved in teaching and learning activities is tremendous and this has become one of the factors in the less production of scientific research and publication. More teaching hours will reduce the time for research; long hours of clinical teaching as well will compromise the quality of research. This is the greatest barrier to a quality and full complement research by most dental academics (Grossman \& Naidoo, 2012). The perceived time constraint and high demand in teaching workload were listed as one of the main barriers for research activities even though the academics were given an allocated time for teaching, research and administration hours. (Nguyen Q. et al., 2016). This situation would have intensified among Malaysian academics who claimed that they were not given allocated time as such.

In addition to remarkable teaching and learning workload as dental academics, the increase of students' intake and erosion number of dental academics makes it hard to sustain adequate clinical teaching and research involvements (Rushton \& Horner, 2008). The same scenario can be seen in the 
dental institution in Malaysia where the intake of dental student increased in the past 5 years to cater national agenda in reducing dentist population ratio. Ministry of Health and Ministry of Education aims to reduce the proportion of dentist to the population to 1: 3000 by 2018. This is a way forward to become an industrialised and developed country by 2020. According to the World Health Organisation (WHO), the average dentist to population ratio in industrialised countries is 1:2000 (Petersen, 2003). The increased intake of dental students would compromise the quality of teaching as the group become bigger and the contact hour of one student to one lecturer become lesser.

Another barrier that been highlighted by the study participant was a financial limitation and inadequate facilities. Grossman \& Naidoo (2012) supported these two factors as the barrier in research productivity even though the majority of their respondents believed that research is an important instrument as dental academics. These two factors play important roles as the main resources for a study to be conducted. Hence the lack of funding and inadequate facilities reported by dental academic in Malaysian would compromise the quality and quantity of research productivity in Malaysia.

Internal factors that have been identified as a barrier to research activity in this study was lacking training and knowledge on research and scientific writing. Research knowledge is a critical component in research productivity and research-related activities which includes scholar knowledge in (a) developing quality research review, (b) delivering sound research methodology (research design; sampling, data collection and data analysis), (c) circulating research findings in scholarly reports i.e., publications in refereed journals (Lambie et al., 2014). In addition to that, information literacy is the fundamental skills involve in accessing data and information. It involves the ability to identify access, locate, use, evaluate and access effectively information for research purposes and informational needs. In most academic library, information literacy training is given on a regular basis to academicians and students to support teaching and research purposes. Researchers need to equip themselves with the ability to access information to their research work such as accessing library electronic and physical resources (books, online database, journal articles, theses, reports and, proceedings). Awareness of the availability of data and information may lead to efficient use of information resources and vibrant knowledge productivity (Brettle, 2008; Carlson et al., 2011; Storie \& Campbell, 2012). The insufficient and lacking of training and knowledge on research methodology, scientific writing and information literacy contribute to the low input of research activities among Malaysia academics.

\section{Conclusion}

The Malaysia government has emphasized on research and innovation with the aim to become competitive and relevant globally. Universities are aware of the impact of research production on global rankings. This study recommends to strengthen the motivational factors and reduce the barriers found in this study at both institution and national level. It is also hoped that there will be an independent body to future discussing on this matter in order to provide recommendations and suggestions for the future development of a research-conducive environment in Malaysia. 
INTERNATIONAL JOURNAL OF ACADEMIC RESEARCH IN BUSINESS AND SOCIAL SCIENCES

Vol. 9, No. 13, Special Issue: Revolutionizing Education: Challenges, Innovation, Collaboration., 2019, E-ISSN: 2222-6990 @ 2019 HRMARS

\section{Acknowledgments}

The researchers wish to thank Research Management Institute, Universiti Teknologi MARA, Malaysia for funding this research project through the Lestari Grant Scheme (Ref: 600-IRMI/DANA 5/3/LESTARI (0067/2016).

\section{References}

Abu-Hassan, M. I. (2010). Dental education in Malaysia: journey towards excellence. Shah Alam, Malaysia: University Publication Centre.

Adams, J. D., \& Griliches, Z. (2000). Research productivity in a system of universities. In The economics and econometrics of innovation (pp. 105-140). Springer, Boston, MA.

Avkiran, N. K. (2001). Investigating technical and scale efficiencies of Australian universities through data envelopment analysis. Socio-Economic Planning Sciences, 35(1), 57-80.

Brettle, A. (2003). Information skills training: a systematic review of the literature. Health Information \& Libraries Journal, 20, 3-9.

Butler, L. (2003). Explaining Australia's increased share of ISI publications - the effects of a funding formula based on publication counts. Research policy, 32(1), 143-155.

Carlson, J., Fosmire, M., Miller, C. C., \& Nelson, M. S. (2011). Determining data information literacy needs: A study of students and research faculty. portal: Libraries and the Academy, 11(2), 629657.

Elservier Research Intelligence (2015). World of Research 2015. Elservier.

Grossman, E. S., \& Naidoo, S. (2012). Academic-service partnerships, research, and the South African Dental Academic. Journal of dental education, 76(9), 1226-1233.

loannidou, E., D'Souza, R. N., \& MacDougall, M. J. (2014). Gender equity in dental academics: gains and unmet challenges. Journal of dental research, 93(1), 5-7.

Kim, T., \& Schallert, D. L. (2014). Mediating effects of teacher enthusiasm and peer enthusiasm on students' interest in the college classroom. Contemporary Educational Psychology, 39(2), 134144.

Kunter, M., Frenzel, A., Nagy, G., Baumert, J., \& Pekrun, R. (2011). Teacher enthusiasm: Dimensionality and context specificity. Contemporary Educational Psychology, 36(4), 289301.

Lambie, G. W., Hayes, B. G., Griffith, C., Limberg, D., \& Mullen, P. R. (2014). An exploratory investigation of the research self-efficacy, interest in research, and research knowledge of Ph. D. in education students. Innovative Higher Education, 39(2), 139-153.

Ministry of Education Malaysia (2015). Malaysia Education Blueprint 2015-2025 (Higher Education). Kuala Lumpur: Ministry of Education Malaysia.

Nguyen, Q., Klopper, C., \& Smith, C. (2016). Affordances, barriers, and motivations: engagement in research activity by academics at the research-oriented university in Vietnam. Open Review of Educational Research, 3(1), 68-84.

Pau, A., Omar, H., Khan, S., Jassim, A., Seow, L. L., \& Toh, C. G. (2017). Factors associated with faculty participation in research activities in dental schools. Singapore dental journal, 38, 45-54.

Petersen, P. E. (2003). The World Oral Health Report 2003: continuous improvement of oral health in the 21st century-the approach of the WHO Global Oral Health Programme. Community Dentistry and oral epidemiology, 31, 3-24. 
Rushton, V. E, Horner, K. (2008). Academic dentistry. Journal of Dentistry, 36(7):472-80.

Shepherd, K. R., Nihill, P., Botto, R. W., \& McCarthy, M. W. (2001). Factors influencing pursuit and satisfaction of academic dentistry careers: perceptions of new dental educators. Journal of Dental Education, 65(9), 841-848.

Storie, D., \& Campbell, S. (2014). Determining the information literacy needs of a medical and dental faculty. Journal of the Canadian Health Libraries Association/Journal de l'Association des bibliothèques de la santé du Canada, 33(2), 48-59.

Suryani, I., Yaacob, A., Hashima, N., Rashid, S. A., \& Desa, H. (2013). Research publication output by academicians in public and private universities in Malaysia. International Journal of Higher Education, 2(1), 84.

Looy, V. B., Callaert, J., \& Debackere, K. (2006). Publication and patent behavior of academic researchers: Conflicting, reinforcing or merely co-existing? Research policy, 35(4), 596-608. 